\title{
Verticillium Wilt Caused by Verticillium dahliae and V. nonalfalfae in Potato in Northern China
}

Rui Jing, Haiyuan Li, Xiaoping Hu, and Wenjing Shang, ${ }^{\dagger}$ State Key Laboratory of Crop Stress Biology for Arid Areas, College of Plant Protection, Northwest A\&F University, Yangling, Shaanxi 712100, China; Ruiqing Shen and Chengjin Guo, Plant Protection Institute, Ningxia Agriculture and Forestry Academy, Yinchuan, Ningxia 750002, China; Qingyun Guo, Key Laboratory of Agricultural Integrated Pest Management In Qinghai Province, Academy of Agriculture and Forestry Science, Qinghai University, Xining, Qinghai 810016, China; and Krishna V. Subbarao, Department of Plant Pathology, University of California, Davis, Salinas, CA 93905

\begin{abstract}
Potato (Solanum tuberosum L.) is one of the most important staple foods in many parts of the world including China. In recent years, Verticillium wilt has become a severe threat to potato production in China. During 2015 to 2016, 287 samples of symptomatic potato plants were collected from 15 counties in five provinces from northern China. One hundred and eighty-seven Verticillium-like colonies were isolated from these samples and identified to species based on cultural and morphological characteristics, and multigene phylogeny based on the partial sequences of actin (ACT), elongation factor 1-alpha $(E F 1 \alpha)$, glyceraldehyde-3-phosphate dehydrogenase (GPD), and tryptophan synthase (TS) genes. A consensus-rooted most parsimonious phylogenetic tree was generated from the data. One hundred and fifteen isolates comprising $61.5 \%$ of the total were identified as Verticillium dahliae, and the remaining $38.5 \%$ of the isolates were identified as $V$. nonalfalfae. V. dahliae was widely distributed in Shaanxi (84.1\%), Inner Mongolia (76.7\%), Gansu (12.8\%), and Qinghai (100\%, representing a

single isolate). $V$. dahliae was not recovered from the samples in Ningxia. V. nonalfalfae dominated the collections from Gansu (87.2\%) and Ningxia (100\%) but was also recovered from Shaanxi (15.9\%) and Inner Mongolia (23.3\%) at lower frequencies. Neither $V$. albo-atrum nor $V$. alfalfae was recovered from the sampled areas. The $V$. nonalfalfae isolates were predominantly isolated from the samples collected from altitudes above $1,800 \mathrm{~m}$, and in contrast, $V$. dahliae isolates were mainly recovered from fields sampled below $1,800 \mathrm{~m}$. The optimum temperature for the colony growth of $V$. nonalfalfae was lower $\left(20^{\circ} \mathrm{C}\right)$ than that for $V$. dahliae $\left(25^{\circ} \mathrm{C}\right)$. Pathogenicity tests demonstrated that $V$. dahliae and $V$. nonalfalfae were both pathogens of potato Verticillium wilt, with $V$. dahliae isolates exhibiting higher virulence than $V$. nonalfalfae isolates regardless of the collection area of the species. This is the first documentation of $V$. nonalfalfae infecting $S$. tuberosum in China and the higher altitudes associated with infections of $V$. nonalfalfae anywhere in the world.
\end{abstract}

Potato (Solanum tuberosum L.), a member of the Solanaceae family, is fourth among the staple food crops in the world following wheat, rice, and corn (Desjardins et al. 1995). More than a billion people worldwide consume potato, and the annual global production exceeds 300 million metric tons (https://cipotato.org/crops/potato/). China and India accounted for nearly one third of the world's potato yield and since 2009, potato production in China has surpassed all nations (Jia et al. 2011; Li and Yang 2016). Verticillium wilt is a common disease and a major threat to potato production throughout the world (Powelson and Rowe 1993; Rowe et al. 1987; Rowe and Powelson 2002). The pathogen colonizes xylem elements following successful infection and interferes with water uptake, leading to foliar discoloration, necrosis, and wilt (Rowe and Powelson 2002). Yield losses caused by Verticillium wilt typically range from 10 to $15 \%$ but can reach up to $50 \%$ in severely affected fields (Johnson et al. 1986; Powelson and Rowe 1993).

Verticillium dahliae and V. albo-atrum were previously considered the causal agents of Verticillium wilt of potato (Pegg and Brady 2002; Rowe and Powelson 2002), but recent reassessment of the taxonomy of the genus Verticillium showed that V. albo-atrum

${ }^{\dagger}$ Corresponding author: W. Shang; E-mail: shangwj@nwsuaf.edu.cn.

Funding: The study was sponsored by the National Natural Science Foundation of China (31371888) and partially by The Open Foundation of the Key Laboratory of Agricultural Integrated Pest Management, Qinghai University (2017-ZJ-Y16) and by the Pilot Project of Scientific and Technical Innovation, Ningxia Academy of Agriculture and Forestry Sciences (NKYJ-15-33).

*The $\boldsymbol{e}$-Xtra logo stands for "electronic extra" and indicates that one supplementary table is published online.

Accepted for publication 7 April 2018.

() 2018 The American Phytopathological Society was not the major pathogen causing Verticillium wilt of potato (Inderbitzin et al. 2011a). The V. albo-atrum species reported in previous literature was likely what is currently taxonomically referred to as $V$. nonalfalfae. It has a limited host range, and relies on the melanized hyphae to survive in soil. Verticillium wilt caused by $V$. albo-atrum is distributed in cooler climatic regions, where average temperatures do not exceed $21^{\circ} \mathrm{C}$ during the growing season (Powelson and Rowe 2008; Rowe et al. 1987). V. tricorpus, $V$. nigrescens (now named Gibellulopsis nigrescens), and $V$. nubilum can also infect potato and other plants, but they are considered as weak pathogens or soil saprotrophs (Barbara and Clewes 2003; Isaac 1949; Pegg and Brady 2002; Slattery and Eide 1980). In contrast, V. dahliae causes vascular wilt diseases on more than 200 plant species worldwide (Pegg and Brady 2002). It can survive as microsclerotia in field soil for 10 years or more (Menzies and Griebel 1967). Thus, once a field is infested by $V$. dahliae, the disease becomes a significant constraint in production. Verticillium wilt of potato was typically uncommon in China, but it was recently observed in Gansu Province and the causal agent was determined to be $V$. dahliae (Chen et al. 2013).

The taxonomy of the genus Verticillium has a long and complicated history. The genus used to contain about 190 species (Zare et al. 2004), which were distinguished by the resting structure morphology, conidia size, conidiophore size and pigmentation, number of phialides per whorl, and the formation of yellow-pigmented hyphae (Inderbitzin et al. 2011a). However, with the advent of molecular systematics, most of the distantly related species were removed from the genus Verticillium, including plant pathogenic species such as $V$. nigrescens and $V$. theobromae (now named as Musicillium theobromae) (Zare et al. 2007), which reduced the number of species within the genus Verticillium to five (Barbara and Clewes 2003). Using multigene phylogeny, in a landmark study, Inderbitzin et al. (2011a) added five new species to this genus (Barbara and Clewes 2003), including $V$. zaregamsianum, V. isaacii, V. klebahnii, V. alfalfae, and $V$. nonalfalfae (Inderbitzin et al. 2011a). However, pathogens 
causing Verticillium wilt of potato have so far not been investigated systematically.

Owing to the importance of potato crop in China and the emerging Verticillium wilt that threatens its production, it is important to characterize the causal agents and develop disease management methods to sustain production. The objectives of this study were therefore to characterize isolates of Verticillium obtained from symptomatic potato plants from production fields in northern China and to determine the distribution of the different species causing Verticillium wilt as influenced by the ecozones of potato production in northern China.

\section{Materials and Methods}

Sample collection and pathogen isolation. From 2015 to 2016, 26 potato fields were sampled from 15 counties of Gansu, Ningxia, Shaanxi, Inner Mongolia, and Qinghai provinces during potato flowering, when symptoms were easily observed. The number of surveyed fields depended on the Verticillium wilt incidence in the potato fields in each province. Four fields were sampled from Gansu, four from Ningxia, nine from Shaanxi, eight from Inner Mongolia, and one field from Qinghai (Table 1). Individual fields varied in size, ranging from one-tenth of a hectare to one-half hectare as most growers in China are small land holders. Plants showing characteristic Verticillium wilt symptoms were sampled from severely diseased fields. The number of plants sampled per field depended on observed disease severity with 11 to 25 plants sampled from severely symptomatic fields ( $>25 \%$ of plants showed symptoms) and 3 to 10 plants sampled from lesser symptomatic fields $(<25 \%$ of plants showed symptoms). Additional information regarding the sampled fields is listed in Table 1. Disease incidence within each field was assessed by walking the fields in an $\mathrm{X}$ pattern and the disease status recorded for 20 plants along each of the four transects. Stems of random symptomatic plants ranging from 3 to 25 were collected from each location where disease severity was assessed and returned to the laboratory for pathogen isolation.

Symptomatic stems were cut into 1- or 2-cm pieces, surface disinfested with $75 \%$ alcohol for 5 to $10 \mathrm{~s}$, rinsed with sterile distilled water three times, air-dried on sterile filter paper for $3 \mathrm{~min}$, and then plated onto potato dextrose agar (PDA) amended with $100 \mu \mathrm{g} \mathrm{ml}^{-1}$ streptomycin sulfate. The plates were incubated at $25 \pm 1^{\circ} \mathrm{C}$ in the dark. Verticillium-like colonies that grew from plated stems were transferred to fresh PDA plates, single-spored, and stored at $-80^{\circ} \mathrm{C}$ as conidial suspensions diluted with glycerol (25\%) for later use.

Morphological characterization and colony growth of isolates. The identification of Verticillium was initially based on morphological characteristics as outlined by Inderbitzin et al. (2011a). All isolates were examined for colony morphology and pigmentation on

Table 1. Verticillium wilt disease incidence and Verticillium species isolated from potato stem samples collected from commercial production fields across northern China

\begin{tabular}{|c|c|c|c|c|c|c|}
\hline Province, Field & Altitude (m) & Cultivar & Disease incidence (\%) & $\begin{array}{l}\text { Number of } \\
\text { samples }\end{array}$ & $\begin{array}{l}\text { Number of } \\
\text { V. dahliae }\end{array}$ & $\begin{array}{c}\text { Number of } \\
\text { V. nonalfalfae }\end{array}$ \\
\hline Gansu & & & & 64 & 5 & 34 \\
\hline Lijiabaozhen, Andingqu & 1,939 & Unknown & 56 & 9 & 5 & 0 \\
\hline Xiangquanzhen, Andingqu & 2,063 & Shepody & 74 & 21 & 0 & 13 \\
\hline Huichuanzhen, Weiyuan & 2,270 & Unknown & 60 & 19 & 0 & 15 \\
\hline Gaofengxiang, Andingqu & 2,565 & Unknown & 65 & 15 & 0 & 6 \\
\hline Ningxia & & & & 22 & 0 & 11 \\
\hline Zhonghexiang, Yuanzhouqu & 1,802 & Zhuangshu 3 & 8 & 10 & 0 & 7 \\
\hline Malianxiang, Xiji & 1,895 & Qingshu 9 & 5 & 5 & 0 & 2 \\
\hline Xitanxiang, Xiji & 1,978 & Qingshu 9 & 4 & 4 & 0 & 2 \\
\hline Xinyingxiang, Xiji & 2,077 & Unknown & 1 & 3 & 0 & 0 \\
\hline Shaanxi & & & & 101 & 53 & 10 \\
\hline Yuyangqu & 1,200 & Shepody & 1 & 5 & 1 & 1 \\
\hline Yangqiaopanzhen, Jingbian & 1,230 & $1106-7$ & 1 & 4 & 2 & 1 \\
\hline Muhuguanzhen, Shangzhouqu & 1,254 & Unknown & 1 & 11 & 1 & 0 \\
\hline $\begin{array}{l}\text { Sidahaocun, Bainijingzhen, } \\
\text { Dingbian }\end{array}$ & 1,355 & Unknown & 0 & 3 & 0 & 0 \\
\hline $\begin{array}{l}\text { Zhangluokengcun, } \\
\text { Bainijingzhen, Dingbian }\end{array}$ & 1,370 & Zihuabai & 4 & 7 & 3 & 0 \\
\hline $\begin{array}{l}\text { Shuanghaizicun, Bainijingzhen, } \\
\text { Dingbian }\end{array}$ & 1,390 & Unknown & 70 & 18 & 16 & 0 \\
\hline $\begin{array}{l}\text { Yanggaocun, Dongkengzhen, } \\
\text { Jingbian }\end{array}$ & 1,500 & Zihuabai & 50 & 12 & 2 & 6 \\
\hline $\begin{array}{l}\text { Caoyaoxiancun, Dongkengzhen, } \\
\text { Jingbian }\end{array}$ & 1,500 & $\begin{array}{l}\text { Zihuabai, } \\
\text { Jizhangshu } 12\end{array}$ & 18 & 16 & 10 & 0 \\
\hline Wangzequzhen, Jingbian & 1,510 & Zihuabai, Shepody & 61 & 25 & 18 & 2 \\
\hline Inner Mongolia & & & & 97 & 56 & 17 \\
\hline $\begin{array}{l}\text { Hongqinghezhen, Ejin Horo } \\
\text { Banner }\end{array}$ & 1,320 & Unknown & 85 & 24 & 19 & 0 \\
\hline Subuergazhen, Ejin Horo Banner & 1,420 & Kexin 1 & 45 & 8 & 6 & 0 \\
\hline Jiningqu, Ulanqab & 1,402 & Unknown & 1 & 5 & 0 & 2 \\
\hline $\begin{array}{l}\text { Sanchakouxiang, Chahar Right } \\
\text { Front Banner }\end{array}$ & 1,450 & Favorita & 1 & 7 & 1 & 2 \\
\hline Bayinxilezhen, Zhuozi & 1,580 & Favorita & 70 & 23 & 16 & 5 \\
\hline $\begin{array}{l}\text { Sanshengtaicun, Kezhen, } \\
\text { Wuchuan }\end{array}$ & 1,600 & Kexin 1 & 30 & 13 & 6 & 5 \\
\hline $\begin{array}{l}\text { Daluerhaocun, Kezhen, } \\
\text { Wuchaun }\end{array}$ & 1,680 & Shepody & 55 & 11 & 6 & 2 \\
\hline $\begin{array}{l}\text { Hongpanxiang, Chahar Middle } \\
\text { Front Banner }\end{array}$ & 1,700 & Kexin 1 & 2 & 6 & 2 & 1 \\
\hline Qinghai & & & & 3 & 1 & 0 \\
\hline Taizixiang, Huzhu & 2,535 & Unknown & 5 & 3 & 1 & 0 \\
\hline Total & & & & 287 & 115 & 72 \\
\hline
\end{tabular}


PDA, morphological features including mycelia, conidia, verticillately arranged phialidic conidiophores, and resting structure were also recorded for each isolate by examining the cultures using a compound microscope (Olympus BX51, Japan). Colony morphology was captured using a Canon $80 \mathrm{D}$ camera. The width and length of 80 conidia from five isolates representing each species were measured using a compound microscope. These data identified two species of Verticillium from among the isolates.

To determine the response of the two species to temperature, five isolates of each species were incubated at $15,20,25$, and $30^{\circ} \mathrm{C}$ on complete medium $(\mathrm{CM})$ (dextrose $10 \mathrm{~g}$, peptone $2 \mathrm{~g}$, yeast extract $1 \mathrm{~g}$, acid hydrolyzed complex proteins $1 \mathrm{~g}, \mathrm{NaNO}_{3} 6 \mathrm{~g}, \mathrm{KCl} 0.5 \mathrm{~g}$, $\mathrm{MgSO}_{4} \cdot 7 \mathrm{H}_{2} \mathrm{O} 1 \mathrm{~g}, \mathrm{KH}_{2} \mathrm{PO}_{4} 1.5 \mathrm{~g}$, ager $15 \mathrm{~g}$, water 1 liter). A 5$\mathrm{mm}$-diameter agar disk containing mycelial growth of each isolate was obtained from the edge of 2-week-old colonies of each isolate and transferred to the center of five plates containing CM. The plates were incubated at each temperature and the diameters of colonies were measured at 2-day intervals until the growth reached the edge of the plates in any one treatment. The experiment was repeated once.

DNA extraction and PCR amplification. The conidial suspensions from each isolate were spread on PDA plates covered in advance with cellophane membrane and mycelia were collected 5 days later. DNA was extracted from each isolate using CTAB method described by Zolan and Pukkila (1986). Four protein coding genes employed (Inderbitzin et al. 2011a) in our study included partial sequences of actin (ACT), glyceraldehyde-3-phosphate dehydrogenase $(G P D)$, elongation factor 1-alpha (EFl $\alpha)$, tryptophan synthase (TS), and the primer pairs for polymerase chain reaction (PCR) amplification employed were: VActF/VActR for $A C T$, VEFf/VEFr for $E F 1 \alpha$, VGPDf2/VGPDr for GPD, and VTs3f/VTs3r for TS. Additional details regarding primer sequences, amplicon length, and annealing temperature followed were as described in Inderbitzin et al. (2011b). All primers were synthesized by Invitrogen (Shanghai, China). PCR was run with EasyTaq DNA Polymerase provided by TransGen Biotech company (Beijing, China) in a $25 \mu$ l reaction volume, and the PCR procedure consisted of an initial denaturation step for 5 min at $94^{\circ} \mathrm{C}$, then 35 cycles of denaturation at $94^{\circ} \mathrm{C}$ for $30 \mathrm{~s}$, annealing for $30 \mathrm{~s}$ at the related primer pair, extension for $1 \mathrm{~min}$ at $72^{\circ} \mathrm{C}$, and final extension at $72^{\circ} \mathrm{C}$ for $10 \mathrm{~min}$. The PCR products were detected in a $1 \%$ agarose gel electrophoresis and were photographed with UV transilluminator (AlphaImager EP, U.S.A.), and all of the correct PCR products were sequenced with the corresponding forward primers by Invitrogen (Shanghai, China). The resulting sequences were compared by Basic Local Alignment Search Tool (BLAST) against the National Center for Biotechnology Information (NCBI) database, and the Verticillium sequences with greater than $99 \%$ sequence homology were downloaded for phylogenetic analyses (Supplementary Table S1). The sequence data for two representative strains of each Verticillium species were obtained from GenBank and used in the phylogenetic analyses.

Phylogenetic analysis. All single-gene sequences were aligned using CLUSTALX version 1.83 with the default settings and edited by BioEdit to eliminate the ambiguously aligned positions and divergent regions prior to phylogenetic analyses. The combined four-locus dataset for all isolates were analyzed using maximum parsimony in Molecular Evolutionary Genetics Analysis (MEGA) 6 with the default settings, and bootstrap supports were based on 1,000 replicates. Gibellulopsis nigrescens sequence from GenBank was chosen as an outgroup. A partition homogeneity test was performed in PAUP* version $4.0 \mathrm{~b} 10$ using 1,000 random repetitions to determine whether the $A C T, G P D, E F$, and $T S$ sequence data could be combined. Tree length, consistency index (CI), retention index (RI), and rescaled consistency index (RC) were calculated using MEGA6.

Pathogenicity test. Pathogenicity tests of five $V$. nonalfalfae isolates from each province and five $V$. dahliae isolates were performed on potato (Table 2). Since the status of $V$. dahliae as a pathogen of potato is well established, only five isolates were tested in contrast to higher number of isolates of $V$. nonalfalfae. Potato tubers (cv. Atlantic) obtained from Gansu Ailan Potato Seed Company (Dingxi, China) were planted into $15-\mathrm{cm}$-diameter pots filled with pasteurized

Table 2. Mean disease severity and relative marginal effects for Verticillium wilt severity on potato caused by $V$. nonalfalfae and $V$. dahliae isolates

\begin{tabular}{|c|c|c|c|c|}
\hline \multirow[b]{2}{*}{ Species, Isolates } & \multirow[b]{2}{*}{ Source } & \multirow{2}{*}{$\frac{\text { Disease severity }^{\mathrm{a}}}{\text { Mean }}$} & \multicolumn{2}{|c|}{ Relative marginal effects ${ }^{b}$} \\
\hline & & & Estimate & $95 \% \mathrm{CI}$ \\
\hline \multicolumn{5}{|l|}{ V. nonalfalfae } \\
\hline WLCBJNQ201 & Chahar Middle Front Banner & 3.0 & 0.39 & $(0.24-0.57)$ \\
\hline WC137 & Wuchuan & 3.4 & 0.50 & $(0.32-0.69)$ \\
\hline WC37 & Wuchuan & 3.0 & 0.40 & $(0.22-0.62)$ \\
\hline ZZ015 & Zhuozi & 3.8 & 0.64 & $(0.47-0.77)$ \\
\hline ZZ018 & Zhuozi & 3.6 & 0.62 & $(0.44-0.77)$ \\
\hline DXWY059 & Weiyuan & 3.5 & 0.56 & $(0.42-0.69)$ \\
\hline DXADQ037 & Andingqu & 2.3 & 0.15 & $(0.08-0.27)$ \\
\hline DXWY076 & Weiyuan & 3.3 & 0.47 & $(0.35-0.59)$ \\
\hline DXADQ033 & Andingqu & 3.1 & 0.43 & $(0.29-0.58)$ \\
\hline DXADQ043 & Andingqu & 3.4 & 0.52 & $(0.35-0.69)$ \\
\hline JB87 & Jingbian & 3.0 & 0.38 & $(0.27-0.51)$ \\
\hline JB058 & Jingbian & 3.0 & 0.39 & $(0.24-0.57)$ \\
\hline JB183 & Jingbian & 3.0 & 0.38 & $(0.27-0.51)$ \\
\hline JB066 & Jingbian & 3.1 & 0.42 & $(0.32-0.52)$ \\
\hline JB192 & Jingbian & 2.8 & 0.32 & $(0.16-0.54)$ \\
\hline GYZH027 & Yuanzhouqu & 3.4 & 0.51 & $(0.38-0.65)$ \\
\hline GYXJ022 & Xiji & 3.0 & 0.40 & $(0.22-0.62)$ \\
\hline GYXJ021 & Xiji & 3.0 & 0.40 & $(0.22-0.62)$ \\
\hline GYZH024 & Yuanzhouqu & 3.9 & 0.66 & $(0.47-0.81)$ \\
\hline GYZH003 & Yuanzhouqu & 3.3 & 0.47 & $(0.27-0.68)$ \\
\hline \multicolumn{5}{|l|}{ V. dahliae } \\
\hline DXADQ054 & Andingqu & 4.1 & 0.73 & $(0.54-0.86)$ \\
\hline DB083 & Dingbian & 4.0 & 0.69 & $(0.48-0.84)$ \\
\hline YQ204 & Ejin Horo Banner & 3.8 & 0.64 & $(0.47-0.77)$ \\
\hline WC 225 & Wuchuan & 3.9 & 0.68 & $(0.53-0.80)$ \\
\hline JB187 & Jingbian & 4.1 & 0.73 & $(0.54-0.86)$ \\
\hline
\end{tabular}

${ }^{\text {a }}$ Disease severity was assessed on a scale of 1 to $5: 1=$ no disease symptoms, $2=$ slight wilting and discoloration of lower leaves, $3=$ moderate wilting involving less than $1 / 2$ of the leaves on the plants, $4=$ severe wilting involving more than $1 / 2$ of the leaves on the plants, $5=$ plant dead from wilt (Hunter et al. 1968).

${ }^{\mathrm{b}}$ Relative marginal effect and $95 \%$ CI were calculated from analysis of the rank values of disease severity. 
sand/potting soil mixture $(2: 1, \mathrm{v} / \mathrm{v})$. Plants were grown in a controlled environment greenhouse $\left(25 \pm 3^{\circ} \mathrm{C}\right.$ with a photoperiod of $\left.14 \mathrm{~h}\right)$ for 4 weeks. Spore suspensions from each isolate cultivated on PDA for 7 days were prepared by adding sterile distilled water and scraping the cultures with a sterile spatula. The concentration of conidia in the suspension from each isolate was adjusted to approximately $10^{7}$ conidia/ml (Vallad et al. 2006) using a hemacytometer. Eight 4week-old potato plants were inoculated by flooding the soil around the roots with $30 \mathrm{ml}$ spore suspensions for each isolate, and eight seedlings were inoculated with $30 \mathrm{ml}$ sterile deionized water as a control. Plants were arranged in a completely random design on greenhouse benches. Inoculated plants were monitored for Verticillium wilt symptom development relative to the uninoculated control plants weekly. Disease severity was recorded on each plant at 7 weeks postinoculation using a scale of 1 to 5 in which: $1=$ no disease symptoms, 2 = slight wilting and discoloration of lower leaves, $3=$ moderate

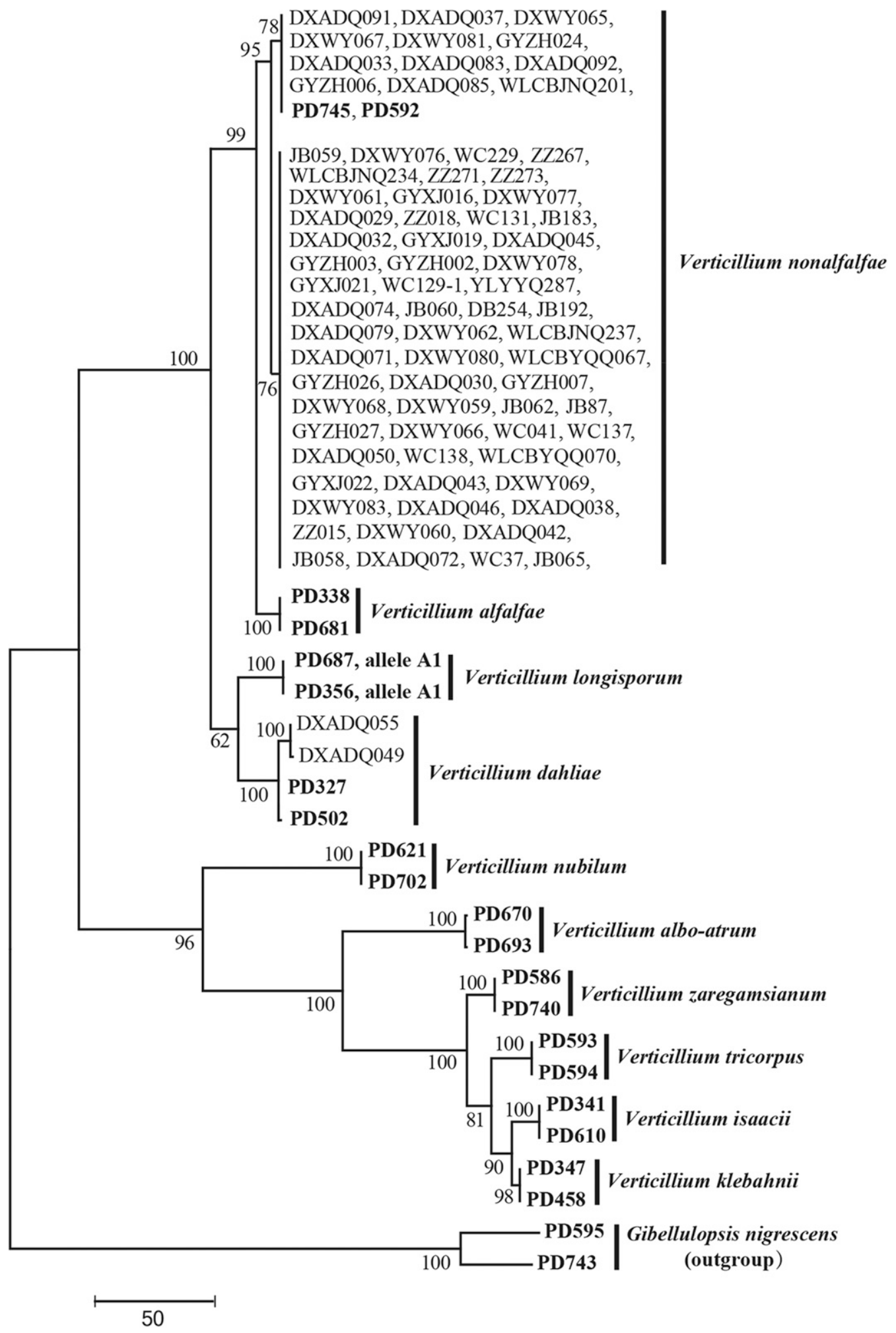

Fig. 1. Most parsimonious rooted tree based on the $A C T, E F, G P D$, and $T S$ sequences of isolates of Verticillium species inferred from maximum parsimony analysis using MEGA 6. Gibellulopsis nigrescens as outgroup. PD identifiers in bold are representative isolates of the different Verticillium species. DXADQ = Andingqu; $D X W Y=$ Weiyuan; $\mathrm{GYZH}=$ Yuanzhouqu; GYXJ = Xiji; JB = Jingbian; DB = Dingbian; YLYYQ = Yuyangqu; ZZ = Zhuozi; WLCBJNQ = Jiningqu; WC = Wuchuan; WLCBYQQ = Chahar Right Front Banner; WLCBYZQ = Chahar Middle Front Banner. 
wilting involving less than $1 / 2$ of the leaves on the plants, $4=$ severe wilting involving more than $1 / 2$ of the leaves on the plants, $5=$ plant dead from wilt (Hunter et al. 1968). The fungi were reisolated from diseased plants as described above. The plates were incubated at $20 \pm 1{ }^{\circ} \mathrm{C}$ or $25 \pm 1^{\circ} \mathrm{C}$ in the dark and the number of plants that were developed symptoms for either $V$. nonalfalfae or $V$. dahliae, respectively, was recorded after 7 days incubation.

Data analysis. The mean colony diameter and standard deviation were calculated from five $V$. dahliae isolates and five $V$. nonalfalfae isolates with five plates for each isolate. The disease severity caused by $V$. dahliae and $V$. nonalfalfae was analyzed by the analysis of variance type statistic of ranked data using the PROC Mixed procedure in SAS version 8.0, and relative marginal effects (RME) was generated using the procedure of LD_CI macro and the 95\% confidence intervals were constructed (Ghosh 2003; Shah and Madden 2004).

\section{Results}

Wilt incidence and isolation of Verticillium spp. from different provinces in China. Verticillium wilt incidence on potato from 26 fields was variable between and within the provinces of Gansu (four fields), Ningxia (four fields), Shaanxi (nine fields), Inner Mongolia (eight fields), and Qinghai (one field), China. In Gansu, the incidence of Verticillium wilt in four fields was $>50 \%$. In contrast, the incidence in Ningxia and Qinghai fields was less than $10 \%$. The incidence varied greatly from 0 to $70 \%$ in the fields in Shaanxi, and from 1 to $85 \%$ in the fields in Inner Mongolia (Table 1). In Shaanxi, the incidence in three out of nine fields was $>50 \%$, and the incidence in five fields was $<5 \%$. In Inner Mongolia, the incidence in three out of eight fields was $>50 \%$, and the incidence in three fields was $<5 \%$ (Table 1 ).

One hundred and eighty-seven Verticillium isolates were recovered from 287 symptomatic potato stem samples. Of the total recovered isolates, 39.0, 33.7, 20.9, 5.9, and $0.5 \%$ were recovered from Inner Mongolia, Shaanxi, Gansu, Ningxia, and Qinghai, respectively. One hundred and fifteen isolates identified as $V$. dahliae accounted for $61.5 \%$ of all isolates; the remaining 72 isolates were $V$. nonalfalfae (38.5\%). V. dahliae accounted for 84.1, 76.7, and $12.8 \%$ of the total in Shaanxi, Inner Mongolia, and Gansu, respectively. Only one $V$. dahliae isolate was recovered from Qinghai and no $V$. dahliae isolates were recovered from Ningxia. $V$. nonalfalfae accounted for 100, 87.2, 23.3, and $15.9 \%$ of the total in Ningxia,

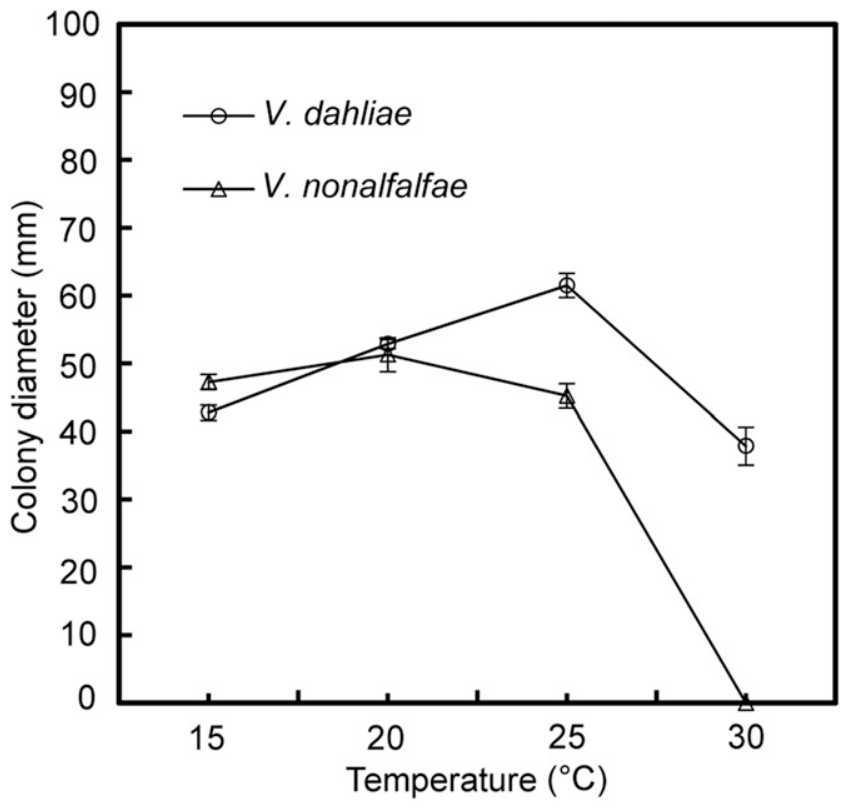

Fig. 2. Effect of temperature on the colony diameters of $V$. dahliae and $V$. nonalfalfae isolates. The average colony diameter from five isolates each from V. dahliae (YQ204, DXADQ054, WC225, DB083, and JB187) and V. nonalfalfae isolates (DXADQ043, WC37, ZZ018, GYZH027, and JB192) with the corresponding standard deviation are shown after 15 days of incubation. All cultures were grown on complete medium (CM).
Gansu, Inner Mongolia, and Shaanxi, respectively. The high proportion of $V$. nonalfalfae isolates were recovered from fields located at altitudes above 1,800 m areas; for example, 87.2 and $100 \%$ of the total isolates were $V$. nonalfalfae in Gansu and Ningxia, respectively. However, V. dahliae isolates were mainly collected from the fields located at altitudes below $1,800 \mathrm{~m}$ in Shaanxi (84.1\%) and Inner Mongolia (76.7\%) (Table 1).

Identification of the strains. Based on characteristics of resting structures, all isolates were classified into two distinct categories with the melanized microsclerotia or brown pigmented hyphae. The first category consisted of 115 Verticillium isolates, and all isolates only formed melanized microsclerotia and no other resting structures were detected. These characteristics matched earlier descriptions for $V$. dahliae (Inderbitzin et al. 2011a). The second category consisted of 72 isolates. which only formed thick-walled and brown resting mycelia. These characteristics matched earlier descriptions for $V$. alboatrum, V. alfalfae, and V. nonalfalfae (Inderbitzin et al. 2011a).

A consensus-rooted most parsimonious phylogenetic tree with a multigene phylogenetic analysis generated using gene sequences of $A C T, E F 1 \alpha, G P D$, and $T S$, provided the most parsimonious tree showing two major clades of the Verticillium species (length $=$ $779, \mathrm{CI}=0.81, \mathrm{RI}=0.94, \mathrm{RC}=0.76, \mathrm{HI}=0.17)$. The representative isolates, DXADQ049 and DXADQ055, were grouped within the $V$. dahliae clade (100\% bootstrap support). Since the results of the morphological identification had indicated that isolates in the first category were $V$. dahliae, only two representative isolates from first category were tested to validate the results from morphological identification. Isolates in the second category that only formed the resting mycelia were grouped into the clade of $V$. nonalfalfae $(95 \%$ bootstrap support) (Fig. 1).

Response of $V$. dahliae and $V$. nonalfafae to temperature. The maximum growth of $V$. dahliae isolates occurred at $25^{\circ} \mathrm{C}$, whereas for $V$. nonalfalfae, it occurred at $20^{\circ} \mathrm{C}$. All isolates within each species responded similarly to temperature. Colony diameters of $V$. dahliae isolates increased with increasing temperature up to $25^{\circ} \mathrm{C}$ and then declined. In contrast, colony diameters of $V$. nonalfalfae isolates increased with increasing temperatures up to $20^{\circ} \mathrm{C}$ and then declined, with growth completely arrested at $30^{\circ} \mathrm{C}$ (Fig. 2).

Pathogenicity test. All 20 isolates of $V$. nonalfalfae and the five isolates of $V$. dahliae tested caused symptoms of Verticillium wilt of potato. The initial wilt symptoms began as yellowing of the foliage. Uneven chlorosis was observed on the lower leaves, and the extension of the discoloration was delimited by the veins. Wilted leaves curled upward with uneven necrosis of leaves that progressed acropetally from the stem base (Figs. 3A and C). Finally, the entire plant became necrotic and wilted with the dead plants remaining erect. The vasculature of infected plants was discolored 7 weeks after inoculation (Figs. 3D and F). Symptoms observed in greenhouse inoculated plants were identical to the wilt symptoms observed in the fields. No distinction between the vascular discoloration caused by $V$. dahliae and $V$. nonalfalfae could be made. $V$. dahliae and $V$. nonalfalfae were reisolated from infected plants and were confirmed to be identical to the inoculated strains based on the morphological characteristics.

The relative virulence of the two species on potato was significantly different with $V$. dahliae isolates exhibiting greater virulence than $V$. nonalfalfae. Chlorosis of lower leaves caused by $V$. dahliae occurred at 17 days postinoculation, while potato plants inoculated with $V$. nonalfalfae showed symptoms at 21 days postinoculation. The $V$. nonalfalfae isolates from each province caused Verticillium wilt on potato. Disease severity caused by these isolates varied from 2.3 to 3.9 on a 1 to 5 point scale (Table 2). In contrast, disease severity caused by each of the $V$. dahliae isolates was higher than that caused by $V$. nonalfalfae and varied from 3.8 to 4.1 (Table 2).

\section{Discussion}

Verticillium wilt is a major economic disease and causes significant yield losses in all potato production regions (Powelson and Rowe 1993; Rowe and Powelson 2002). Even though China is the largest potato producer in the world, the status of Verticillium wilt 
in potato is still uncertain except for the recent report of $V$. dahliae causing the disease in Gansu Province (Chen et al. 2013). As demonstrated by this study, Verticillium wilt is widespread in the potato production fields that were sampled across all provinces even though the relative severity of the disease was different among the provinces. In Gansu Province, the Verticillium wilt was most severe in all surveyed fields, but in Ningxia Province, the disease was least severe. The severity of disease varied greatly among the fields in Shaanxi and Inner Mongolia. While this study provides a snapshot of the current status of the disease, as observed in other systems (Atallah et al. 2011), once introduced, the pathogen not only establishes itself in individual fields but rapidly spreads from these foci to new fields with the planting of infested seeds in new fields and/or movement of soil and equipment between fields. Thus, the disease is likely to emerge as a major threat to potato production in China.

Both $V$. dahliae and $V$. nonalfalfae were demonstrated to be causal agents of Verticillium wilt on potatoes in China but their relative importance differed among the different provinces where potato production occurs. V. dahliae was the dominant species in Shaanxi and Inner Mongolia, whereas $V$. nonalfalfae was the predominant species causing the disease in Ningxia and Gansu. Previously, V. dahliae and V. albo-atrum were the known causes of Verticillium wilt elsewhere in the world (Pegg and Brady 2002; Rowe and Powelson 2002). Neither $V$. albo-atrum nor $V$. alfalfae, another species split-off from V. albo-atrum, was found in any fields evaluated in this study. This is the first report of $V$. nonalfalfae as a pathogen of potato or any other crop in China.

Climate (altitude and the associated temperature) appear to play an important role in the distribution of the two species causing Verticillium wilt in potato. Previously, V. dahliae was the predominant cause of Verticillium wilt on potato in production areas where average daily summer temperatures commonly exceeded $27^{\circ} \mathrm{C}$. In contrast, V. albo-atrum was the predominant cause of Verticillium wilt in production areas where average daily temperatures did not reach $21^{\circ} \mathrm{C}$ (Powelson and Rowe 2008; Rowe et al. 1987). Similarly, we found that $V$. dahliae was distributed production fields located primarily at altitudes below 1,800 m. For example, in Shaanxi Province, $84.1 \%$ of the total isolates collected at altitudes between 1,200 and $1,510 \mathrm{~m}$ were $V$. dahliae. Similarly, in Inner Mongolia, $76.7 \%$ of the total isolates collected at altitudes between 1,320 to $1,700 \mathrm{~m}$ were $V$. dahliae. However, $V$. nonalfalfae was the primary causal agent in fields located above $1,800 \mathrm{~m}$. For example, $V$. nonalfalfae $(87.2 \%)$ was collected primarily at altitudes between 1,939 and $2,565 \mathrm{~m}$ in Gansu Province. Similarly, V. nonalfalfae (100\%) was collected at altitudes between 1,802 to $2,077 \mathrm{~m}$ in Ningxia. In these two provinces and at these altitudes, the average daily temperatures do not exceed $20^{\circ} \mathrm{C}$ during the potato growing season (Guo et al. 2006; Yao et al. 2008). This is further supported by the optimum temperature for colony growth of $V$. nonalfalfae being lower $\left(20^{\circ} \mathrm{C}\right)$ than that for $V$. dahliae $\left(25^{\circ} \mathrm{C}\right)$. We therefore posit that temperature plays an
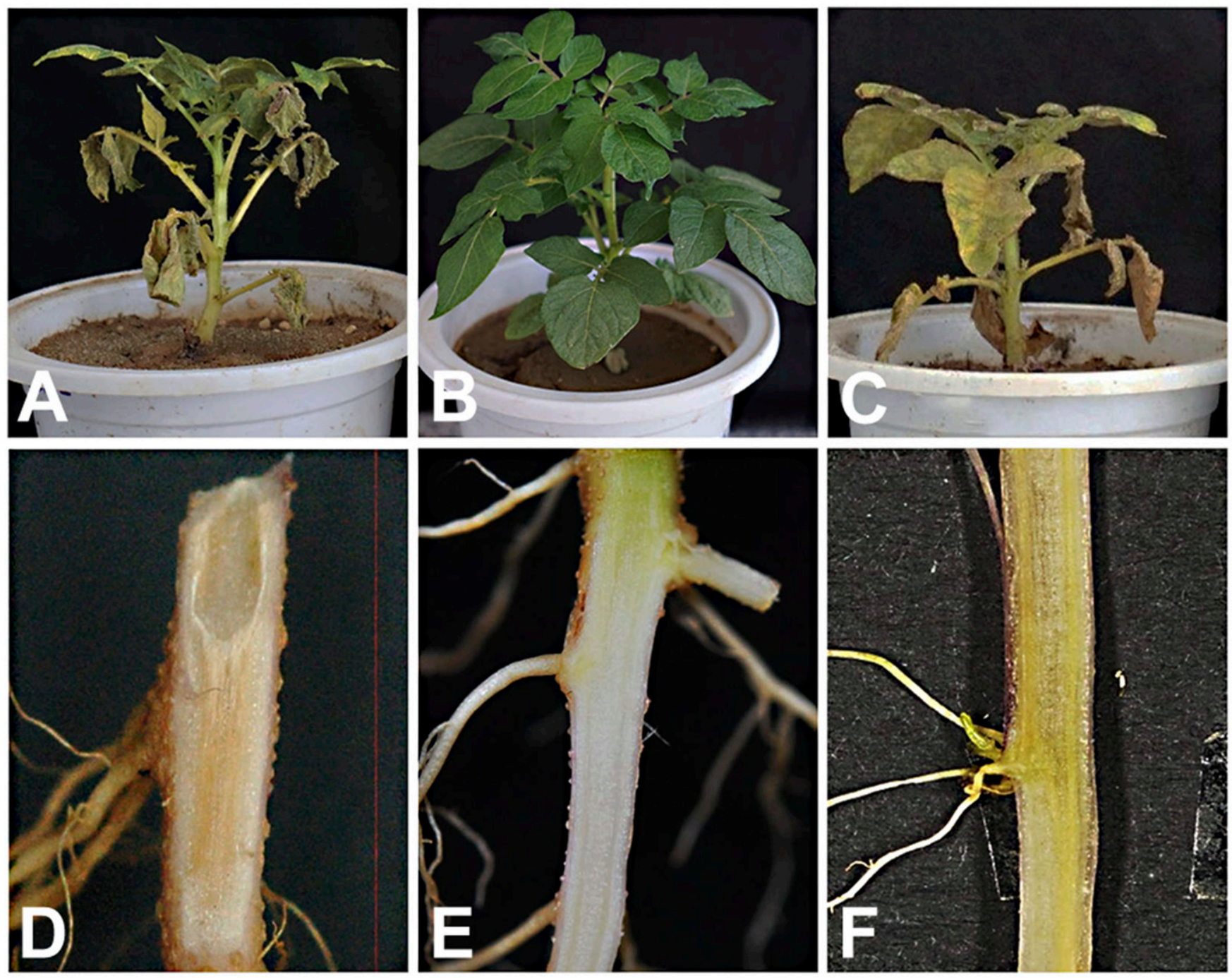

Fig. 3. Foliar and root symptoms of Verticillium wilt on potato seedlings caused by $V$. dahliae and $V$. nonalfalfae compared with the uninoculated control. A, D, symptom caused by V. nonalfalfae GYZH024 strain at 7 weeks postinoculation; C, F, the symptom caused by V. dahliae DXADQ054 strain at 7 weeks postinoculation; B, E, the control plants with no disease symptoms. 
important role in the distribution of the two species causing Verticillium wilt in China. The above results regarding the response of the two species to temperature are consistent with the results of Rowe et al. (1987), even though their study compared $V$. dahliae and $V$. albo-atrum. The significantly novel results from this study are the association of the lower temperature requirement of $V$. nonalfalfae with the higher altitudes of the potato fields from which the majority of these isolates were collected and the association of the higher temperature requirement of $V$. dahliae with the lower altitudes of the potato fields from which the majority of these isolates were collected. Together, the temperature and altitude may determine the relative survival of the two species indirectly and this needs further study.

The taxonomy of the genus Verticillium has significantly changed since these species were first reported as causing disease on potato. Initially, $V$. albo-atrum was reported as the pathogen of Verticillium wilt on potato (Reinke and Berthold 1879). V. dahliae was subsequently identified from dahlia (Klebahn 1913), and then both V. dahliae and $V$. albo-atrum were determined to be the primary pathogens on potato (Krikun and Orion 1979). V. albo-atrum in turn was divided into two clear subspecific groups based on host specificity (L, comprising the host adapted isolates from lucerne, and NL, comprising isolates from all other hosts) (Heale and Isaac 1963), and the division was also strongly supported by studies involving several molecular markers (Morton et al. 1995; Okoli et al. 1993). A further study subdivided $V$. albo-atrum into $V$. albo-atrum group 1 and $V$. albo-atrum group 2 by sequencing of the rRNA ITS regions (Robb et al. 1993). The majority of the $V$. albo-atrum group 2 isolates came from potato (or soil from fields where potatoes had been grown) from eastern Canada, Maine (U.S.A.), and the Netherlands (Europe) (Mahuku and Platt 2002; Robb et al. 1993). With the establishment of a new taxonomic framework for Verticillium, $V$. alfalfae and $V$. nonalfalfae were described as the two new species from V. albo-atrum (Inderbitzin et al. 2011a), and the three species are morphologically indistinguishable. Inderbitzin et al. (2011a) speculated that the name ' $V$. albo-atrum' has possibly been applied more frequently to ' $V$. albo-atrum' group 1 now comprising $V$. alfalfae and $V$. nonalfalfae, than to ' $V$. albo-atrum' group 2, which is now retained as $V$. albo-atrum. Regardless of the taxonomy, the current study provides an appraisal of the importance of Verticillium wilt in potato production in China and the pathogens that cause the disease and their relative distribution. Neither $V$. alfalfae nor $V$. albo-atrum was isolated from potato samples in China. Because of the similarity of the temperature requirements between $V$. nonalfafae and $V$. albo-atrum, we can speculate that the pathogen in the previous reports in all likelihood indeed was $V$. nonalfalfae.

$V$. nonalfalfae has been reported as the cause of vascular wilt on hops, Solanaceous crops, spinach, and forest and shade trees in Canada, Japan, Cuba, Slovenia, the United Kingdom, and the United States (Hiemstra 1998; Inderbitzin et al. 2011a; Pegg and Brady 2002; Schall and Davis 2009). Based on the results from this study, we add potato, another Solanaceous crop, to the list of hosts of $V$. nonalfalfae. The relative agricultural importance of this new species and its host range among the crops remains to be determined.

\section{Acknowledgments}

We would like to express our sincere thanks to Hongsheng Shang, Zhouquan Wei, Aichang Chen, Ruiqing Shen, Chengjin Guo, and Yaodong Wen, who helped collect the samples from various locations in China.

\section{Literature Cited}

Atallah, Z. K., Hayes, R. J., and Subbarao, K. V. 2011. Fifteen years of Verticillium wilt of lettuce in America's salad bowl: A tale of immigration, subjugation and abatement. Plant Dis. 95:784-792.

Barbara, D. J., and Clewes, E. 2003. Plant pathogenic Verticillium species: How many of them are there? Mol. Plant Pathol. 4:297-305.

Chen, A. C., Wei, Z. Q., Ma, Y. Q., and Deng, C. G. 2013. Isolation and identification of the pathogens causing potato Verticillium wilt in Gansu. Acta Phytopathol. Sin. 43:418-420 (in Chinese with English abstract).

Desjardins, A. E., Mccormick, S. P., and Corsini, D. L. 1995. Diversity of sesquiterpenes in 46 potato cultivars and breeding selections. J. Agric. Food Chem. 43:2267-2272.
Ghosh, S. 2003. Nonparametric analysis of longitudinal data in factorial experiments. Technometrics 45:171-172.

Guo, Z. F., Yang, G. H., and Zhang, Z. L. 2006. Analysis on the development of potato industry in Guyuan. Chin. Potato J. 20:312-314 (in Chinese with English abstract).

Heale, J. B., and Isaac, I. 1963. Wilt of lucerne caused by species of Verticillium. Ann. Appl. Biol. 52:439-451.

Hiemstra, J. A. 1998. A compendium of Verticillium wilts in tree species. Ponsen and Looijen, Wageningen, The Netherlands.

Hunter, D. E., Darling, H. M., Stevenson, F. J., and Cunningham, C. E. 1968 Inheritance of resistance to Verticillium wilt in Wisconsin. Am. Potato J. 45 $72-78$

Inderbitzin, P., Bostock, R. M., Davis, R. M., Usami, T., Platt, H. W., and Subbarao, K. V. 2011a. Phylogenetics and taxonomy of the fungal vascular wilt pathogen Verticillium, with the descriptions of five new species. PLoS One 6:e28341.

Inderbitzin, P., Davis, R. M., Bostock, R. M., and Subbarao, K. V. 2011 b. The ascomycete Verticillium longisporum is a hybrid and a plant pathogen with an expanded host range. PLoS One 6:e18260.

Isaac, I. 1949. A comparative study of pathogenic isolates of Verticillium. Trans. Br. Mycol. Soc. 32:137-157.

Jia, J. X., Yang, D. Q., Li, J. D., and Li, Y. 2011. Research and comparative analysis about potato production situation between China and continents in the world. Agric. Eng. 1:84-86 (in Chinese with English abstract).

Johnson, K. B., Radcliffe, E. B., and Teng, P. S. 1986. Effects of interacting populations of Alternaria solani, Verticillium dahliae, and the potato leafhopper (Empoasca fabae) on potato yield. Phytopathology 76:1046-1052.

Klebahn, H. 1913. Beiträge zur Kenntnis der Fungi Imperfecti I. Eine VerticilliumKrankheit auf Dahliaen. Mycologisches Zentralbl. 3:49-66.

Krikun, J., and Orion, D. 1979. Verticillium wilt of potato: importance and control Phytoparasitica 7:107-116.

Li, Z. H., and Yang, X. J. 2016. Analysis on potato industry of world and China. Food Nutr. China 22:5-9 (in Chinese with English abstract).

Mahuku, G. S., and Platt, H. W. 2002. Molecular evidence that Verticillium alboatrum Grp 2 isolates are distinct from V. albo-atrum Grp 1 and V. tricorpus. Mol. Plant Pathol. 3:71-79.

Menzies, J. D., and Griebel, G. E. 1967. Survival and saprophytic growth of Verticillium dahliae in uncropped soil. Phytopathology 57:703-709.

Morton, A., Carder, J. H., and Barbara, D. J. 1995. Sequences of the internal transcribed spacers of the ribosomal RNA genes and relationships between isolates of Verticillium albo-atrum and V. dahliae. Plant Pathol. 44:183-190.

Okoli, C. A. N., Carder, J. H., and Barbara, D. J. 1993. Molecular variation and sub-specific groupings within Verticillium dahliae. Mycol. Res. 97:233-239.

Pegg, G. F., and Brady, B. L., eds. 2002. Verticillium Wilts. CABI International, Wallingford, UK

Powelson, M. L., and Rowe, R. C. 1993. Biology and management of early dying of potatoes. Annu. Rev. Phytopathol. 31:111-126.

Powelson, M. L., and Rowe, R. C. 2008. Managing diseases caused by seedborne and soilborne fungi and fungus-like pathogens. Pages 183-195 in: Potato Health Management. D. A. Johnson, ed. The American Phytopathological Society, St. Paul, MN

Reinke, J., and Berthold, G. 1879. Die zersetzung der kartoffel durch pilze. Untersuchungen Aus Dem Bot. Laboratorium Univ. Gottingen 1:67-96.

Robb, J., Moukhamedov, R., Hu, X., Platt, H., and Nazar, R. N. 1993. Putative sub-groups of Verticillium albo-atrum distinguishable by PCR-based assays. Physiol. Mol. Plant Pathol. 43:423-436.

Rowe, R. C., Davis, J. R., Powelson, M. L., and Rouse, D. I. 1987. Potato early dying: causal agents and management strategies. Plant Dis. 71:482-489.

Rowe, R. C., and Powelson, M. L. 2002. Potato early dying: managemen challenges in a changing production environment. Plant Dis. 86:1184-1193.

Schall, M. J., and Davis, D. D. 2009. Verticillium wilt of Ailanthus altissima: susceptibility of associated tree species. Plant Dis. 93:1158-1162.

Shah, D. A., and Madden, L. V. 2004. Nonparametric analysis of ordinal data in designed factorial experiments. Phytopathology 94:33-43.

Slattery, R. J., and Eide, C. J. 1980. Prevalence of Verticillium wilt in potatoes in the Red River Valley area of Minnesota. Am. Potato J. 57:293-299.

Vallad, G. E., Qin, Q. M., Grube, R., Hayes, R. J., and Subbarao, K. V. 2006. Characterization of race-specific interactions among isolates of Verticillium dahliae pathogenic on lettuce. Phytopathology 96:1380-1387.

Yao, Y. B., Zhang, C. J., Wan, X., Luo, D. G., Zhang, X. Y., Shi, J., and Chang, J. H. 2008. Relationships between development of potato late blight and the meteorological conditions on the loess plateau: a case study on Dingxi of Gansu Province. Plant Prot. 34:90-92 (in Chinese with English abstract).

Zare, R., Gams, W., and Schroers, H. J. 2004. The type species of Verticillium is not congeneric with the plant-pathogenic species placed in Verticillium and it not the anamorph of 'Nectria' inventa. Mycol. Res. 108:576-582.

Zare, R., Gams, W., Starink-Willemse, M., and Summerbell, R. C. 2007 Gibellulopsis, a suitable genus for Verticillium nigrescens, and Musicillium, a new genus for $V$. theobromae. Nova Hedwigia 85:463-489.

Zolan, M. E., and Pukkila, P. J. 1986. Inheritance of DNA methylation in Coprinus cinereus. Mol. Cell. Biol. 6:195-200. 